\title{
Intracellular magnesium content changes during mitochondria-mediated apoptosis: in depth study of early events on mitochondrial membrane potential
}

\author{
Lucia Merolle, ${ }^{1}$ Concettina Cappadone, ${ }^{1}$ Giovanna Farruggia, ${ }^{1,2}$ Chiara Marraccini, ${ }^{3}$ \\ Azzurra Sargenti, ${ }^{1}$ Alessia Colanardi, ${ }^{4}$ Stefano lotti ${ }^{1,2}$ \\ ${ }^{1}$ Department of Pharmacy and Biotechnologies, University of Bologna; ${ }^{2}$ National Institute of \\ Biostructures and Biosystems, Roma; ${ }^{3}$ Department of Life Sciences, University of Modena and \\ Reggio Emilia; ${ }^{4}$ Institute of Translational Pharmacology - CNR, L'Aquila, Italy
}

\begin{abstract}
A recent study showed the antitumor activity of a new indole-derivative - MM-67 - inducing mitochondria-mediated apoptosis and a decrease of intracellular magnesium (Mg) concentration in HT29 colon cancer cells. Aim of this work was to assess cellular Mg levels throughout MM-67-induced apoptosis from the early to the final stage of the process and to evaluate the correlation with mitochondrial membrane potential $(\Delta \Psi \mathrm{m})$ variations. All analysis were performed by flow cytometry: $\Delta \Psi \mathrm{m}$ was assessed by using mitochondrial potential sensitive dye DiOC6, while free and total intracellular cation concentrations were assessed by using the commercial probe MagFluo4-AM ( $\mathrm{Kd}=4.7 \mathrm{mM})$, and the new synthesized DCHQ5 ( $\mathrm{Kd}=8.3 \mathrm{mM})$, respectively. Our results evidenced that the MM67 induced apoptosis is characterized by a direct correlation between $\Delta \Psi$ and free intracellular Mg content variations.
\end{abstract}

\section{Introduction}

Not only is apoptosis a genetically controlled mechanism essential for the maintenance of tissue homeostasis, development and elimination of unwanted cells, but it is also a commonly accepted mechanism of antineoplastic effect for chemotherapeutic agents. Cations are important in apoptosis since they regulate protein activation in

Correspondence: Lucia Merolle, Department of Pharmacy and Biotechnologies, University of Bologna, via Belmeloro 6, 40126 Bologna, Italy. Tel.Fax: +39.051.2099700.

E-mal: lucia.merolle@unibo.it

Key words: apoptosis, magnesium, indole-derivative, colon cancer.

(C) Copyright M: Merolle et al., 2014

Licensee PAGEPress, Italy

Journal of Biological Research 2014; 87:2139

doi:10.4081/jbr.2014.2139

This article is distributed under the terms of the Creative Commons Attribution Noncommercial License (by-nc 3.0) which permits any noncommercial use, distribution, and reproduction in any medium, provided the original author(s) and source are credited. different signal transduction pathways. Recently, the influence of $\mathrm{Mg}^{2+}$ ion on apoptosis is gaining increasing attention, even if the available literature on this topic is still scarce and often ambiguous. Recent study showed the antitumor activity of a new indole-derivative - MM67 - inducing mitochondria-mediated apoptosis and affecting intracellular magnesium $(\mathrm{Mg})$ concentration in HT29 colon cancer cells. ${ }^{1}$ Forty-eight h of MM67 treatment induce arrest in G2/M phase, significant enhancement of the expression of Bax protein, depolarization of mitochondria membrane potential $(\Delta \Psi \mathrm{m})$, release of cytochrome $c$ from mitochondrial compartment, and decrease of intracellular Mg.

Growing evidences support a role of $\mathrm{Mg}$ in the apoptotic process. ${ }^{2}$ Adenosine triphosphate (ATP) synthesis is regulated by mitochondrial $\mathrm{Mg}$ concentration and it is reported that mitochondrial inner membrane depolarization induces the release of $\mathrm{Mg}$ from mitochondria. ${ }^{3}$ All these experimental evidences strongly support the idea of a link between mitochondrial function and $\mathrm{Mg}$ intracellular homeostasis. Aim of this work was to monitoring Mg fluctuations throughout apoptosis induction from the early to the final stage of the process. The current literature is focused on the relationship between apoptosis and the free ionized $\mathrm{Mg}$ which represents only a $10 \%$ of the total amount. However, it is known that total Mg could have a role in cellular signalling as well, and that bound and free fractions undergo different regulatory mechanisms. For these reasons, beside the ionized form, we measured total intracellular Mg concentrations, exploiting the characteristics of DCHQ5, a new chemosensor of the DCHQ family.

\section{Materials and Methods}

The human HT29 cell line was maintained in Roswell Park Memorial Institute (RPMI) 1640 medium supplemented with 2mM LGlutamine, $10 \%$ foetal bovine serum (FBS) at $37^{\circ} \mathrm{C}$ and $5 \% \mathrm{CO}_{2}$. Cells were treated with MM67 $500 \mathrm{nM}$.

Flow cytometric assays: $\Delta \Psi \mathrm{m}$ was probed with DiOC6 4 for $40 \mathrm{~min}$ at a cell concentration of $1 \times 10^{6} \mathrm{cell} / \mathrm{mL}$ at $37^{\circ} \mathrm{C}$ in the dark. Total $\mathrm{Mg}$ concentration was evaluated by DCHQ5 probe, incubating $1 \times 10^{6}$ cells/mL in phosphate buffered saline (PBS) without $\mathrm{Mg}^{2+}$ for $15 \mathrm{~min}$ in the dark at $37^{\circ} \mathrm{C}$ with $5 \mu \mathrm{M}$ fluorophore, while free $\mathrm{Mg}^{2+}$ was determined incubating the cells with $0.8 \mu \mathrm{M}$ Mag-Fluo4-AM dye for $30 \mathrm{~min}$ at $37^{\circ} \mathrm{C} ., 5$

$\Delta \Psi \mathrm{m}$, free and total $\mathrm{Mg}$ were reported as the percentage of variation of fluorescence intensity of treated cells respect to controls. 


\section{Results}

We evaluated the effect of the indole derivative on mitochondrial membrane potential at $0.5,2$ and $48 \mathrm{~h}$ of treatment. We observed hyperpolarization within first half hour of treatment, followed by a marked depolarization in the next $48 \mathrm{~h}$, as reported in Figure 1.

Free and total cellular Mg concentration were evaluated in HT-29 cells after $0.5,2$ and $48 \mathrm{~h}$ of treatment with MM-67. As shown in Figure $2 \mathrm{~A}$, we found an increase of free intracellular Mg content in the first half hour of treatment, while a decrease was observed in the subsequent hours. On the contrary, total amount decreased already in the early hours (Figure 2B).

\section{Discussion}

The induced apoptosis is characterized by a direct correlation between $\Delta \Psi \mathrm{m}$ and free intracellular Mg content variations. In particular, the early events characterizing the apoptosis induction showed a correlation between $\Delta \Psi \mathrm{m}$ and free intracellular Mg content while no significant variations in the total pool were detected. It is crucial to clarify whether this different behavior that occurs following the apoptotic stimulus was a coincidental event or a causative determinant of the apoptotic cascade. The picture on the role of $\mathrm{Mg}$ in apoptosis is far from being defined: further experimental data are needed to elucidate the involvement of this cation in the apoptotic process.

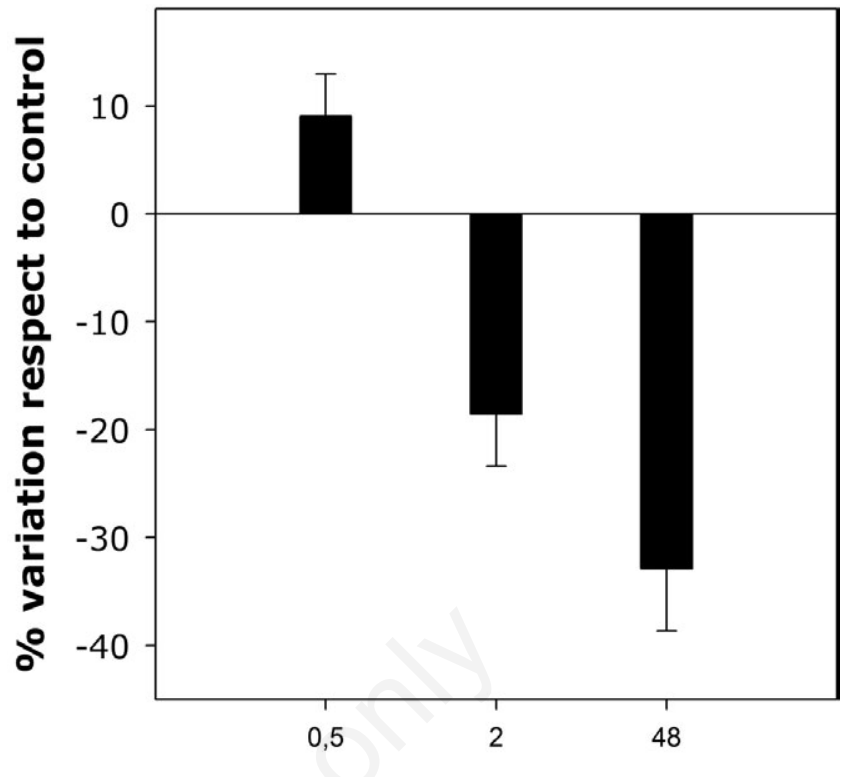

hours of treatment

Figure 1. Effect of MM67 on mitochondria membrane potential in HT-29 cells at $0.5,2$ and $48 \mathrm{~h}$ of treatment.

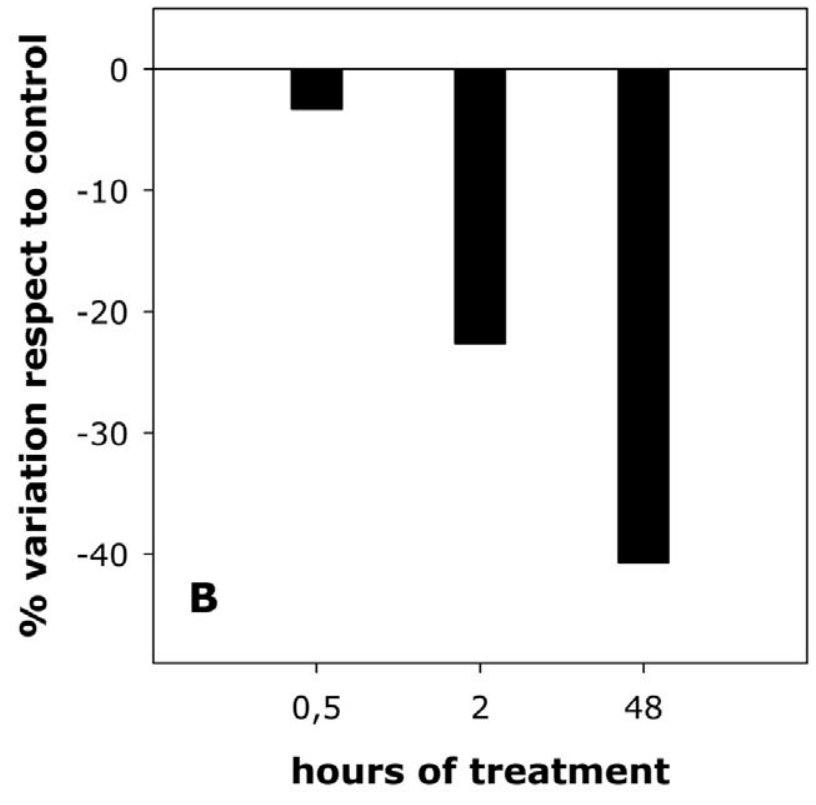

Figure 2. Effect of MM67 on magnesium levels at 0.5, 2 and $48 \mathrm{~h}$ of treatment on HT-29 cells. A) Free ionized magnesium; B) total magnesium. 


\section{References}

1. Andreani A, Granaiola M, Locatelli A, et al. Substituted 3-(5-imidazo[2,1 b]thiazolylmethylene)-2-indolinones and analogues: synthesis, cytotoxic activity, and study of the mechanism of action. J Med Chem 2012;55:2078-88.

2. Cappadone C, Merolle L, Marraccini C, et al. Intracellular magnesium content decreases during mitochondria-mediated apoptosis induced by a new indole-derivative in human colon cancer cells. Magnesium Res 2012;25:104-11.
3. Kubota T, Shindo Y, Tokuno K, et al. Mitochondria are intracellular magnesium stores: investigation by simultaneous fluorescent imaging in PC12 cells. Biochim Biophys Acta 2005;1744:19-20.

4. Marracini C, Farruggia G, Lombardo M, et al. Diaza-18-crown-6 hydroxyquinoline derivatives as flexible tools for the assessment and imaging of total intracellular magnesium. Chem Sci 2012;3;727-34.

5. Lee S, Lee HG, Kang SH. Real-time observations of intracellular $\mathrm{Mg}^{2+}$ signaling and waves in a single living ventricular myocyte cell. Anal Chem 2009;812:538-42. 